\title{
Direito subjetivo e propriedade. Sobre o tomismo de Michel Villey
}

\author{
Alfredo Storck \\ alfredostorck@gmail.com \\ Universidade Federal do Rio Grande do Sul/CNPq, Porto Alegre, Rio Grande do \\ Sul, Brasil
}

\begin{abstract}
resumo Em uma série de importantes livros e artigos, Michel Villey defendeu que a origem do direito subjetivo não deveria ser encontrada no Direito Romano ou na filosofia de Tomás de Aquino, mas no nominalismo criado por Guilherme de 0ckham. 0 objetivo desse artigo consiste em sugerir que a interpretação de Villey é forte demais. Para tanto, o artigo está dividido em três partes. Na primeira, alguns textos importantes do Direito Romano são analisados. A segunda trata da concepção de Tomás acerca da propriedade e do direito. Para concluir, algumas rápidas observações acerca da tese geral de Villey são acrescentadas.
\end{abstract}

palavras-chave Tomás de Aquino; Michel Villey; Ius; direitos subjetivos; propriedade

\section{Michel Villey e o surgimento do direito subjetivo}

Em uma longa série de estudos escritos durante mais de 40 anos, o historiador francês e filósofo do direito, MichelVilley, defendeu uma tese, bastante difundida e razoavelmente bem aceita, acerca da origem do direito subjetivo. Segundo Villey, o direito romano desconheceria essa noção, pois consideraria o direito, o ius, como um atributo legal inerente às coisas externas. O ius seria uma propriedade jurídica das coisas que, ao revesti-las, lhes conferiria certas propriedades. $\mathrm{O}$ ius fruendi seria assim uma propriedade incorpórea da $\operatorname{coisa}^{1}$,já que era a coisa que era descrita e não o poder sobre a coisa.A idéia de um poder subjetivo para reivindicar, de um direito subjetivo portanto, seria uma invenção tardia. Nada mais distante do mundo antigo que a ideia moderna de pensar o direito em função dos indivíduos: 
quais são seus direitos?, como os fazer valer? Isso não significa que os juristas romanos não reconhecessem, por exemplo, o poder do credor de exigir do devedor uma obrigação. Mas esses poderes para agir, essas liberdades, eram tidas por "noções da linguagem vulgar, sobre as quais operam os juristas (...) [,] são um dado anterior à elaboração do direito e permanecem extrajurídicas" (VILLEY, 1962, p. 158). "O direito não é um 'atributo' do indivíduo, isoladamente considerado, mas uma coisa, uma coisa objetiva" (VILLEY, 1962, p. 160). Apresentada a tese, a tarefa do historiador é, em Villey, acompanhada da do filósofo que busca denunciar a imprecisão promovida pelo vocabulário subjetivista moderno e retornar à "linguagem clássica romana, bem mais precisa" evitando assim empregar "expressões que encobrem uma mentira interna, confundindo o direito e a pretensão subjetiva pré-jurídica". (VILLEY, 1962, p. 164).

A obra de Tomás de Aquino é lida porVilley como estando em perfeita sintonia com o ensinamento dos juristas romanos. Mas isso, desde que se procure a teoria do direito no Tratado da Justiça e não no Tratado da Lei, como o fizeram alguns neotomistas. Seguindo a tradição romana e a filosofia aristotélica, Tomás teria definido o ius como aquilo que é justo (quod iustum est) ou como a própria coisa justa (ipsa res iusta). O direito e o justo seriam objetivamente reconhecidos, pois que dependeriam de uma certa ordem do universo e não de convenções arbitrárias e subjetivas. Quanto às leis, elas “são as 'regras das ações humanas', governam a conduta humana, o conjunto da moralidade". Pertencem, portanto, a outro domínio que não o da justiça, já que o "jus 'objeto da justiça' é uma 'coisa', uma realidade, a realidade justa ('res justa'), esta realidade inerente ao corpo político que é nele a justa relação dos bens e das coisas repartidas entre os cidadãos" (VILLEY, 2001).

Ainda segundo o autor francês, o surgimento de um poder (potestas) para reivindicar algo em nome próprio seria o resultado de um subjetivismo tornado apenas possível pela filosofia nominalista de Guilherme de Ockham (VILLEY, 1953-54)2 , mas que teria encontrado seu grande continuador em Thomas Hobbes (VILLEY, 1961 e 1968). O pensador franciscano teria sido o primeiro a entender o ius como potestas, como um poder lícito, pois dada a incapacidade, derivada do nominalismo, de atribuir propriedades às próprias coisas, não haveria ordem jurídica que não fosse precedida por uma vontade particular e não por uma ordem social suprain- 
dividual. Nesse quadro conceitual, "todo direito, no sentido técnico da palavra, é, portanto, um poder: Ele difere da mera 'licença', ou da convenção revogável de que gozam os pobres convidados à festa de um senhor, conforme à parábola do Banquete, e que o senhor pode revogar. Ninguém pode ser privado de seu direito sem causa ou sem seu consentimento" (VILLEY, 1975, p. 248). "Este poder é-nos atribuído pela concessão feita pela lei positiva" (VILLEY, 1975, p. 249). Em uma palavra, o direito subjetivo surgiria da conjugação das noções de direito e poder. No modelo nominalista, o poder absoluto de Deus seria o ápice. Em segundo momento, Deus teria conferido ao homem o poder para apropriar-se das coisas e para instituir regras. Ora, o instituidor de regras tem o poder para legiferar, ou seja, para instituir leis que deveriam garantir a propriedade, o usufruto e o direito de uso, todos direitos subjetivos resguardados pela autoridade. Esses seriam absolutos e poderiam ser exercidos ou renunciados segundo a vontade humana. $\mathrm{Na}$ base dessa interpretação, residiria a tese segundo a qual o nominalismo teria produzido uma concepção não apenas subjetiva, mas egoística, identificada na inclinação de cada pessoa para pensar tudo em termos do seu interesse próprio e pessoal. Haveria assim uma íntima conexão entre direito subjetivo e uma forma de subjetividade egoísta. Retornar ao modelo romano e tomista seria o caminho para evitar a ambos os males.

Nosso objetivo no presente artigo consistirá em fazer algumas observações sobre o tomismo praticado por Villey buscando determinar as razões que o teriam conduzido a identificar em Tomás o campeão da versão objetivista do direito. Para tanto, o artigo dividir-se-á em três partes. Na primeira, passaremos em revista a alguns textos do direito romano clássico buscando determinar a pertinência da tese de Villey. Na segunda, resumiremos alguns elementos bem conhecidos acerca do problema da propriedade na Idade Média e analisaremos a posição de Tomás acerca desse tema. Para finalizar, teceremos algumas observações mais gerais sobre a teoria subjetivista do direito.

\section{Realismo jurídico romano?}

Michel Villey tem razão ao afirmar que não encontramos no direito romano clássico um quadro conceitual fundado em uma concepção 
subjetivista de direitos. Não há nada que se assemelhe aos direitos humanos apresentados, para tomarmos um exemplo absolutamente inconteste, na Declaração Universal dos Direitos do Homem e do Cidadão e que sirva de fundamento último para os demais institutos jurídicos. A concepção de pessoa como sujeito último de direitos inalienáveis e consubstanciais à própria dignidade humana parece, de fato, não somente estranha ao mundo romano, mas ainda algo que teria surgido devido a mudanças históricas bastante fortes e amplamente estudadas pelos especialistas $^{3}$. Criticar Villey tentando encontrar no mundo antigo um sucedâneo dos direitos humanos modernos seria uma tarefa desde o início fadada ao fracasso, como, aliás, admite claramente o crítico mais sistemático de Villey, Brian Tierney ${ }^{4}$. Por outro lado, admitir a inexistência de uma teoria sobre direitos humanos em Roma não significa endossar plenamente a tese segundo a qual toda e qualquer reivindicação de direitos seria relegada ao estrato pré-jurídico e permaneceria incapaz de ser formulada em termos do vocabulário do direito romano clássico.

De acordo com a tese de Villey, o sentido técnico de direito para os juristas romanos seria distante de uma atribuição de poderes a um indivíduo. Se atualmente lemos os institutos romanos em termos de direitos subjetivos, isso se deve à projeção, realizada pelos romanistas modernos, de uma noção estranha ao mundo antigo (VILLEY, 1964, p. 104-106). Um tratado jurídico romano como as Institutas de Gaio (circa 110-179 d.C.) teria por objeto a simples descrição do mundo de um ponto de vista jurídico. Haveria pessoas que desempenham diversos papéis (cidadãos, latinos, peregrinos, escravos, etc), coisas "que servem de decoração ao cenário" e ações humanas, mesmo que apenas as processuais interessariam aos juristas (VILLEY, 1962, p. 173). As coisas seriam divididas em corpóreas, as que podem ser tocadas, e incorpóreas, que não o podem, como a sucessão, o usufruto e as obrigações advindas de contratos (GAIUS, 1991, II, 12). Os direitos de sucessão (ius sucessionis), de usufruto (ius utendi et fruendi) e de obrigação (ius obligationis) seriam classificados por Gaio como coisas incorpóreas e não como poderes para fazer algo, o que leva Villey a concluir pela impropriedade de leituras modernas e subjetivistas. Não há direito de sucessão entendido como direito subjetivo ou poder para suceder. Existe apenas a coisa incorpórea designada 'sucessão'. Gaio aliás usaria indistintamente as expressões 'ius sucessionis' e 
'hereditas' (VILLEY, 1962, p. 180). Os direitos (iura) seriam coisas que poderiam subsistir mesmo sem beneficiários, como no caso das servidões prediais. O mesmo sentido objetivo seria encontrado na definição clássica da justiça como a virtude cujo traço característico seria o de atribuir a cada um o seu ius. O termo ius deve ser aqui interpretado como equivalente a mérito, ou seja, a justiça dá a cada um o que ele merece ou o que é seu. "A cada um seu status, a condição que lhe convém" (VILLEY, 1953-1954, p. 172).

O ponto central de Villey consiste em mostrar que as relações jurídicas eram compreendidas em sentido objetivo. A análise da relação "Cícero possui a propriedade de uma casa" era feita como envolvendo uma pessoa, uma coisa corpórea e uma incorpórea, a própria relação, a proprietas. Ora, basta lembrar a força do pensamento estóico em Roma para não sermos surpreendidos com esse tipo de análise. ${ }^{5} \mathrm{O}$ problema está, todavia, na afirmação de que o direito romano desconheceria qualquer interpretação em termos de atribuição de poderes a indivíduos. Alguns textos tirados também das Institutas de Gaio permitir-nos-ão nuançar a tese de Villey.

Gaio inicia suas Institutas afirmando que todo povo que se rege por leis e costumes segue, em parte, um direito que lhe é próprio e, em parte, um direito que compartilha com todos os seres humanos. O primeiro é chamado direito civil enquanto o segundo é aquele "que a razão natural estabelece entre todos os homens, é observado de maneira semelhante por todos os povos e se chama direito dos povos". A expressão ius aplicase assim tanto à legislação produzida pelos homens, quanto às regras de direito natural. Importa agora perguntar se esses dispositivos apenas estabelecem caracterizações de situações jurídicas em termos de uma definição de papéis, distribuição de méritos e obrigações ou se os romanos concebiam algum tipo de atribuição de poderes ou capacidades por essas regras.

Comecemos analisando as regras do direito natural. Após apresentar os diversos tipos de leis, Gaio cita uma tripla divisão do direito empregado em Roma: "os direitos de que fazemos uso se relacionam todos às pessoas, às coisas ou às ações”. Ora, segundo Villey, a classificação não estaria baseada em direitos subjetivos, ou seja, em poderes garantidos pela lei que poderiam ser usados conforme sua vontade, pois "são descritas primeiramente as 
pessoas e não a capacidade de exercer direitos subjetivos" (VILLEY, 1962, p. 174). De fato, Gaio usa a expressão ius personarum para qualificar, em um primeiro momento, a classificação das pessoas em livres ou servos e, em um segundo, entre aqueles que são autônomos (sui iuris) ou aqueles que são dependentes por estarem submetidos ao direito de outrem (alieno iuri subiectae sunt). Todavia, é digno de nota que, ao retomar essa passagem, o Digesto ${ }^{6}$ cite, imediatamente após, a seguinte definição de liberdade, tirada de Florentino: "A liberdade é a faculdade natural que cada um possui de fazer o que quiser, salvo se impedido por uma força ou pelo direito". Se a tese de Villey vale, então isso deveria significar que o direito (ius) estabeleceria apenas limitações à liberdade e não conferiria poderes para alguém livremente agir ou não. Não haveria propriamente um sujeito dotado de direitos, mas limitações jurídicas à liberdade.

No entanto, a passagem pode ser lida em sentido diverso daquele defendido porVilley. $\mathrm{O}$ ius concede efetivamente o poder para fazer algo, poder que seria usado livremente desde que não houvesse limitação para tanto. A maneira como os glosadores medievais leram esse texto é esclarecedora. Acúrsio (1182-1263) relata haver duas interpretações em disputa. Irnério (circa 1050-1130) sustentava que a liberdade era definida pelo direito natural (ius naturale) de tal sorte que a liberdade do servo estaria igualmente abarcada na caracterização inicial. Também o servo poderia fazer o que quisesse, desde que nenhum impedimento (ou seja, algum fator de natureza não jurídica) ou algum direito de outra ordem (logo, diferente do direito natural) o proibisse. Outros autores afirmavam tratarse apenas da liberdade do homem livre e não da do servo, já que são dois tipos distintos de liberdades. Acúrsio, no entanto, discorda de seus antecessores e explica a faculdade em termos de uma possibilidade concedida pelo direito natural e interpreta o duplo impedimento (força ou outro direito) como se referindo respectivamente ao direito dos povos (pelo qual é servo aquele que foi conquistado pela força) ou ao direito civil. $\mathrm{O}$ debate gira, portanto, em torno de como compreender, de um ponto de vista jurídico, a facultas, a libertas e os seus limites por meio de um vocabulário que deveria ser a marca de uma concepção subjetivista de direitos. Ora, segundo Villey, a liberdade romana seria apenas uma noção filosófica de origem estóica caracterizada em termos de poderes, sem que esses fossem direitos. Todavia, se a noção de liberdade fosse pré-jurídica, 
então não teria sentido caracterizá-la como de direito natural ou mesmo diferenciar tipos de liberdades em funções dos tipos de direitos. Se os juristas definem a faculdade natural como ligada ao direito natural, isso deve significar que o exercício dessa faculdade é o exercício do direito natural. Tem-se assim que a palavra ius é usada tanto para significar uma obrigação ou restrição do campo de ação, como também no sentido de poder ou ter capacidade para algo. Ius serve para qualificar tanto o uso de poderes quanto obrigações.

Tomemos agora exemplos ligados à lei civil. Ao tratar do modo de aquisição da cidadania romana, Gaio elenca diversos modos de um direito para sua obtenção (ius adispiscendae). Por exemplo, com base na lei Aelia Sentia, se um Latino casar com uma cidadã romana, tiver com ela um filho e atestar o fato por sete testemunhas romanas, então um poder lhe é dado por aquela lei (detur eis potestas per eam legem) de se apresentar frente a um pretor e demandar a cidadania (GAIUS, 1991, I, 28-31). Note-se que o indivíduo ainda não é cidadão. Ele possui apenas a capacidade para demandar o reconhecimento de sua condição e terá efetivamente a cidadania após o seu reconhecimento pela autoridade competente. Satisfeitas as condições iniciais, ele possui apenas um poder para demandar e não a própria condição. Adquirir direitos equivale a adquirir poderes para fazer algo, como fica também claro no caso da idade para realizar um testamento. Quando uma mulher completa 12 anos, ela obtém o direito (ius nanciscitur) de fazer um testamento (testamentum facere) (GAIUS, 1991, II, 113). Aliás, um dos primeiros requisitos para a validade de um testamento é possuir o poder para fazê-lo. E ainda que essa capacidade seja descrita em termos gerais, mesmo assim é em virtude dela que a mulher pode realizar o testamento (femina vero potest). Essas breves indicações são suficientes para mostrar que, contrariamente à tese de Villey, o direito romano não ignorava ou relegava para o nível pré-jurídico os poderes conferidos ao indivíduo. De fato, encontramos nas Institutas diversas outras passagens nas quais a lei é dita atribuir direitos ${ }^{7}$, onde as pessoas são ditas possuírem ${ }^{8}$ e usarem direitos ${ }^{9}$.

Podemos concluir que a atribuição de poderes a indivíduos não é totalmente estranha ao mundo romano, sem precisarmos admitir que os juristas do período conhecessem e adotassem a concepção subjetivista de direitos. Villey teria desconsiderado totalmente esse aspecto do pensa- 
mento jurídico antigo para poder dar maior relevo à origem ockamiana da noção de direito subjetivo e o seu contraste com a noção tomista. Devemos agora perguntar se realmente Tomás de Aquino desconhecia completamente essa noção.

\section{Direito e propriedade: as definições tomistas}

Michel Villey encontra em Tomás de Aquino o seguidor da noção clássica de direito. Obviamente, não se trata de uma mera retomada das concepções antigas, sobretudo a de Aristóteles, por oposição ao cristianismo. Bem ao contrário,Villey dedicou mais de um estudo para mostrar a força cristã das ideias de Tomás e o impacto social de seu cristianismo por oposição a certos partidários da doutrina social da Igreja (VILLEY, 1962, p. 203-219 e 1975, p. 149-176).

Para Villey, Tomás procura "fundar a ciência jurídica não sobre 'a natureza do homem' individualmente considerado, como será a estranha pretensão dos modernos e de onde os modernos inferirão esse atributo do homem isolado, seu poder, seu 'direito subjetivo'; mas sobre a base de um dado natural mais fecundo, a partir da observação da ordem presente no corpo social, sobre a "natureza cósmica"' (VILLEY, 1964, p. 103). O direito para Tomás seria, portanto, "isso que é justo, o resultado do trabalho do jurista, a justa relação objetiva, a justa proporção objetiva”. Aplicado ao indivíduo, o ius seria a parte que lhe cabe na justa repartição, uma vez que seria função da justiça atribuir a cada um o seu direito: suum ius cuique tribuere. Tomás, assim como a escola dos glosadores, simplesmente ignoraria o direito subjetivo.

Mais uma vez, julgamos ser a tese exagerada e procuraremos nuançá-la. Villey associa o aparecimento do direito subjetivo com um nominalismo que teria tornado possível a figura de um indivíduo egoísta preocupado apenas com o uso de seus poderes. Ora, a determinação do momento de surgimento da individualidade parece-nos um problema totalmente distinto e os debates acerca desse tema desenvolveram-se de forma independente do seu apregoado vínculo com os direitos ${ }^{10}$. Sendo assim, deixaremos de lado esse aspecto da questão para concentrar-nos na noção de direito. No que segue, faremos um rápido resumo das discussões 
medievais sobre a propriedade nos séculos XII e XIII e, posteriormente, lembraremos a posição de Tomás de Aquino. Por fim, apresentaremos alguns elementos subjetivistas que decorrem dessa apresentação.

\section{Propriedade e justiça na Idade Média11}

Por volta de 1200, o jurista italiano Azo distinguiu a propriedade que era natural daquela que diz respeito ao direito civil. Outros eram contrários a tese, dizendo que não há propriedade que não esteja fundada no ius gentium. Ora, a diferença parece advir de uma ambigüidade das fontes. Nas Institutas de Gaio há referência a modos naturais de adquirir a propriedade, como, por exemplo, a ocupação, a captura da propriedade de um inimigo ou a tradição. No Digesto, no entanto, a tradição e a ocupação parecem ser classificadas como pertencentes ao ius gentium. Ou seja, por um lado, as Institutas parecem apontar para o direito de propriedade como um direito natural, pois a aquisição desta pode ser feita independentemente da existência da autoridade política. Basta admitir a existência de uma coisa de ninguém, de uma res nullius, a qual é adquirida por um modo originário. Por outro, o Digesto parece fazer depender a propriedade da autoridade política, pois ainda que o ius gentium não seja próprio de nenhum povo, ele é dependente da esfera política.

Lembremos, rapidamente que os romanos, a partir de um certo período, passaram a distinguir o ius gentium, ou seja, o direito comum a todos os povos, do direito natural, organizado segundo a razão natural e igual para todos os seres humanos. Assim, o ius gentium configurava um conjunto de normas aplicáveis a todos os que vivem sob a tutela jurídica de Roma, seja cidadão ou estrangeiro. Mas sua aplicação era dependente da relação dos estrangeiros com a autoridade de Roma. Já o direito natural parecia vigorar independentemente dessa relação com a autoridade política.

A ambiguidade acerca da classificação de um dispositivo como de direito natural ou de ius gentium (por exemplo, se o direito que se adquire por ocupação é ou não independente de seu reconhecimento por uma autoridade política) ganha certamente relevância se for lida no contexto das mudanças nas estruturas sociais ocorridas a partir do século XII e das disputas entre senhores e vassalos. De um lado, o senhor 
reivindica o dominium sobre a propriedade e o direito a que ela não fosse alienada sem o seu consentimento e sem a garantia de que o adquirente passasse a lhe servir como vassalo (o que na verdade significava cada vez mais apenas pagar tributos). De outro, o vassalo passava à categoria de possuidor e reivindicava a possessio, a capacidade de utilizar e dispor da propriedade e de se ver excluído da relação de vassalagem após a alienação da propriedade.

É importante também rememorar que, no mesmo período, ocorre o enfraquecimento político dos senhores e o aumento do poder central do rei. Portanto, não era mais perante o senhor que as questões eram debatidas, mas perante o poder real. Observando-se o surgimento histórico de uma nova figura do poder, parece mais fácil entender o peso da questão. Os homens possuem direito sobre as coisas antes que a autoridade política centralizada lhes confira esse direito (ou seja, há um direito natural à propriedade que se manifesta nos modos originários de aquisição?) ou toda a propriedade somente pode ser justificada pela atribuição do poder político (ou seja, todo direito de propriedade é um direito fundado na autoridade política instituída?).

Há assim, no século XIII, uma grande incerteza acerca da distinção entre dominium e possessio. Alguns não viam diferença alguma, enquanto outros entendiam o dominium como uma capacidade passiva sobre o bem e a possessio como o direito ativo a utilizá-lo. Na prática, começa a surgir um esforço para proteger aqueles que detinham a posse. Tanto que Acúrcio propõe distinguir entre o dominium utile, aplicado àquilo que se tinha na qualidade de usufrutuário e dominium indireto, que descrevia um direito abstrato detido normalmente pelo senhor feudal. Ou seja, e é somente isso que nos interessa nessas notas históricas, durante os séculos XIII e $\mathrm{XIV}$, o debate entre os juristas buscava precisar se os direitos dos usuários eram criações de origem convencional e relativos à vida social, do governo civil e das leis, ou se a fusão do dominium e da possesio era uma característica dos homens anteriores aos governos. Possuem os homens direitos sobre as coisas antes que o governo lhes confira esse direito ao reconhecê-los como possuidores de direito? Ou, posto em termos teológicos, a propriedade é natural ao homem ou é natural ao homem somente após a queda? ${ }^{12}$ 


\section{Propriedade e direito em Tomás de Aquino}

Identificada a relevância histórica do problema, passemos agora ao modo como Tomás de Aquino pronuncia-se acerca da necessidade e origem da propriedade privada. Obviamente, no contexto teórico adotado por Tomás, a resposta à pergunta tem como ponto de partida a tese segundo a qual o ser humano é um animal racional. Por um lado, dizer que o ser humano é um animal, implica, aos olhos de Tomás, salientar que ele é um dentre os seres naturais e que, em virtude dessa condição, está teleologicamente orientado para um fim. Melhor dizendo, o fim do ser humano é duplo: na vida futura, a beatitude. Na vida presente, e esse é o ponto relevante aqui, a felicidade. Por outro lado, dizer que o ser humano é racional significa afirmar que a busca desse fim é intencional, vale dizer: as ações humanas orientadas para a busca da felicidade dependem, como o expõe a Summa Contra Gentiles, de quatro princípios:

O primeiro princípio ativo das ações morais reside no objeto apreendido, o segundo, na faculdade apreensiva, o terceiro é a vontade e o quarto é a força motriz que executa as ordens da razão (CG, III, 70).

O fim, portanto, é algo apresentado pela razão, aceito pela vontade e realizado. A ação responsável é aquela na qual o agente age de forma voluntária na busca de um bem. O fim da ação é apresentado à vontade como um bem. A felicidade, fim último das ações humanas, somente pode consistir no bem supremo, cuja natureza é analisada por Tomás tanto na Suma de Teologia e nos Comentários à Ética a Nicômaco onde se mostra que a felicidade imperfeita que se pode alcançar nessa vida somente pode consistir na realização de uma vida completa orientada pela virtude. Como o Comentário a Ética a Nicômaco afirma textualmente:

A felicidade é uma atividade própria do homem orientada pela virtude em uma vida completa (SE, I, 10).

Essa tese e suas consequências são o suporte para três outras relativas à propriedade. Em primeiro lugar, saliente-se que a felicidade é apresentada como o fim último para cada ser humano particular. Portanto, se, por sua condição natural, o ser humano necessariamente está orientado para a busca da felicidade e se essa não se identifica com a posse de bens, o 
máximo que se pode admitir é a importância de bens externos como condição para realização das ações virtuosas nas quais consiste a felicidade. Como mostra a Suma de Teologia, os bens externos são necessários não como pertencendo à essência da felicidade, mas como instrumentos para alcançá-la $(S T$, I II, 4, 7). Essa tese terá repercussões evidentes para o nosso problema. Se, por sua natureza, o ser humano possui um fim último, se a natureza lhe conferiu as condições para alcançá-lo e se esse fim não se identifica com bens externos, necessitando-se deles apenas como meios, então a natureza, ao fornecer as condições materiais para a felicidade, forneceu bens externos como meios. Forneceu assim o direito de usar, mas não forneceu o direito à propriedade, pois que, em primeiro lugar, basta a posse para usar dos bens como meios e, em segundo, não pode ter a natureza fornecido bens de forma exclusiva, sob risco de privar alguns seres humanos das condições materiais para o seu fim.

Saliente-se, além disso, a passagem do fim último do indivíduo particular para o bem comum. Comentando a Política de Aristóteles, Tomás afirma que o homem é, por natureza, um animal social, já que ele necessita de muitas coisas que não pode obter apenas por seu esforço próprio e solitário. Assim, ele faz necessariamente parte de um grupo no qual a assistência lhe é conferida para viver. Ele necessita desse auxílio tanto para viver quanto para viver bem (ST I II, 66, 2). Em primeiro lugar para viver, ou seja, para ter aquelas coisas necessárias e sem as quais a vida na terra não poderia ser vivida. Nesse sentido, o auxílio é conferido ao homem pelo grupo chamado doméstico, pois todo homem depende de seus pais para nascer, alimentar-se e ter educação. Por isso, os membros das famílias ajudam-se uns aos outros com respeito às necessidades da vida. Auxílio de outro tipo é dado por outro grupo do qual o ser humano faz necessariamente parte, pois ele tem por objetivo a realização da vida completa. Ou seja, trata-se do auxílio não apenas para viver, mas para viver bem. E isso é dado pela comunidade política. Essa ajuda diz respeito não apenas aos bens corpóreos na medida em que a cidade possui muitos produtos que a economia doméstica não pode fornecer, mas também às necessidades morais. A vida em comunidade ocupa função especial na educação e formação do ser humano enquanto cidadão. O poder público (publica potestas), por exemplo, ao se fazer temer, refreia os jovens insolentes que não podem ser corrigidos pelas admoestações paternas. 
Em suma, do mesmo modo que o ser humano possui um fim particular que lhe é natural, assim também a organização política está teleologicamente ordenada para um fim: o bem comum da coletividade (cf. KEMPSHALL, 1999). Da mesma forma que a realização de um projeto de vida necessita seguir certos padrões para alcançar o fim, cabe à organização política determinar o modo de divisão dos encargos e benefícios sociais. Essa distribuição dá-se de forma complementar à natureza, pois apenas a posse de bens, e não a sua propriedade exclusiva, é decorrência do direito natural. Assim, faz-se necessária a intervenção política para regrar a distribuição de bens. Tomás analisa a questão na Suma de Teologia e pergunta, em primeiro lugar, se a posse de bens é natural ao ser humano e, após, se a propriedade dos bens o é. Eis a primeira resposta:

Os bens externos podem ser considerados de um duplo modo.

Primeiramente, quanto à sua natureza, que não está submetida ao poder do homem, mas ao poder de Deus, a cuja vontade tudo obedece. Em segundo lugar, quanto ao seu uso. Sob esse aspecto, o homem tem um poder natural (naturale dominium) sobre os bens exteriores, pois pela razão e vontade pode servir-se deles para sua utilidade, como tendo sido feitos para ele. Ora, os seres imperfeitos existem para os seres mais perfeitos. Esse princípio permite a Aristóteles (Política I) provar que a posse (possessio) de bens exteriores é natural ao homem. E esse poder natural sobre as demais criaturas, que o homem possui por sua razão, é o que faz dele imagem e semelhança de Deus (ST, II II, 66, 1).

Note-se que, nos Comentários à Ética a Nicômaco, era a condição natural do homem que era chamada para justificar a posse de bens externos. $\mathrm{Na}$ Suma de Teologia, é Deus que desempenha esse papel. Mas o argumento é basicamente o mesmo. Se a natureza ou Deus criou o ser humano com um fim, então deve tê-lo provido com os meios para alcançá-lo. Logo, a natureza, ou Deus, conforme o caso, forneceu os meios para o ser humano alcançar a felicidade. E é por isso que o ser humano tem a posse natural dessas coisas e pode fazer delas uso.

Na sequência, Tomás de Aquino reforça a ideia segundo a qual é a posse e não a propriedade que é natural. Mas por qual razão teria sido introduzida a propriedade privada? Três são os motivos apresentados (ST, II II, 66, 2). 
1. Cada um confere à gestão do que lhe é próprio cuidados maiores do que daria ao bem comum pertencente a todos ou a muitos, pois nesse caso os indivíduos evitam o esforço e deixam aos demais o cuidado com as coisas comuns;

2. Há mais ordem na administração dos bens quando o cuidado com as coisas é confiado a uma pessoa particular, ao passo que se instalaria a confusão se todos se ocupassem indistintamente de tudo;

3. A paz entre os homens é melhor garantida se cada um está satisfeito com o que lhe pertence.

Após apresentar os motivos para a divisão do que é comum, Tomás reitera que, de forma natural, os bens são disponíveis a todos e cada qual pode fazer deles o uso necessário. Note-se, todavia, que o regime da comunidade de bens é natural não porque o direito natural obriga que tudo deva ser possuído de forma comum e nada seja próprio, mas porque a divisão de bens é estranha à condição natural humana. A divisão tem origem na convenção, por não ser, em primeiro lugar, contrária ao direito natural e, em segundo, por ser mais útil. Em resumo, a definição de felicidade humana como a atividade própria do homem orientada pela virtude em uma vida completa permitiu, até o momento, as seguintes conclusões:

a) A posse comum de todas as coisas é a condição natural do homem;

b) A divisão do comum não é contrária ao direito natural, tem origem no direito positivo (ius positivum) e é decorrência da condição política como organizadora e otimizadora da distribuição de bens (ST, II II, 66, 1, ad 2).

Tomás resume sua posição do seguinte modo:

A posse comum de todas as coisas e a igual liberdade para todos são ditas pertencerem à lei natural (ius naturale), pois a distinção das posses e a escravidão não são produzidas pela natureza, mas pela razão humana para a utilidade da vida humana. E assim a lei da natureza (lex naturae) não foi alterada a esse respeito a não ser por um acréscimo (ST, I II, 94, 5, ad 3).

Ora, se a propriedade privada não pertence ao direito natural, então, pergunta Tomás, em caso de extrema necessidade, seria permitido servirse do que pertence a outrem? A resposta é afirmativa, pois como as regras do direito humano não podem derrogar as do natural ou divino, então, em caso de extrema necessidade, a situação volta a ser regida pelo direito natural. Todavia, pode-se interpretar essa autorização de dois modos: a) 
como uma obrigação de assistência aos necessitados; b) como um direito ao que é comum. No primeiro caso, não haveria um direito do necessitado, mas uma obrigação de auxílio daquele que possui em abundância. ${ }^{13}$ Nesse caso, o ius naturale estabeleceria um dever natural de assistência, de tal sorte que dispositivos do direito natural não confeririam direitos, mas unicamente expressariam deveres. No segundo, poder-se-ia pensar que, como todas as coisas são comuns em estado de extrema necessidade ( $S T$, II II, 32, ad 3), então o necessitado estaria exercendo o seu direito natural. A contrapartida do dever de assistência seria o direito subjetivo aos bens necessários à sobrevivência.

No entanto, não é claro que os textos apontem para essa segunda possibilidade. Tomás aborda a questão perguntando se, em caso de extrema necessidade, haveria furto quando se toma do outro o necessário para viver. Sua tese é a de que a ação é permitida (licet, ST, II II, 32, 7 ad 3) ou que seria mesmo lícito furtar para dar esmolas a necessitados (licitum est, ST, II II, 32, 7 ad 1). Todavia, do modo como Tomás trata do problema, não ocorre aqui propriamente o uso de um direito, mas a realização de uma ação que, normalmente, deveria ser penalizada e que, devido às circunstâncias, é desculpada $(S E, \mathrm{~V}, 13)$. A extrema necessidade é tida por ele mais como um excludente de culpa que propriamente como um exercício de um direito natural.

Há um duplo aspecto desse debate que deve ser salientado. Por um lado, foi exatamente esse o contexto histórico identificado por Tierney como estando na origem do direito subjetivo. Com efeito, a tradição canonista, notadamente Alanus, Laurentius e Hostensis, teria atribuído aos indivíduos, em caso de extrema necessidade, um direito ao uso dos bens (TIERNEY, 1989). Mesmo teólogos, como Godofredo de Fontaines, teriam seguido esse caminho em um período anterior a Ockham (MÄKINEN, 2005b, p. 45-50). Sendo assim, a tese de Villey segundo a qual o nominalismo de Ockham seria o ambiente favorável que estaria na origem da noção de direito subjetivo não pode ser mais aceita e, de fato, tem sido rechaçada pela literatura especializada.

Por outro lado, no entanto, em virtude da análise acima acerca da noção de propriedade, sua origem e seus limites, pareceria que deveríamos dar razão a Villey quanto à inexistência de direitos subjetivos em Tomás de Aquino. Aliás, TIERNEY (1997) e COLEMAN (2006) 


\section{2}

chegam a afirmar que Tomás simplesmente não reconhece situações em que um sujeito está na posse de direitos e pode reivindicá-los. Em outras palavras, a palavra ius não seria jamais empregada por Tomás a não ser para significar a própria coisa justa. ${ }^{14}$

No que segue, gostaríamos de sugerir que é possível, mais uma vez, nuançar a tese de Villey mesmo no que se refere a Tomás de Aquino, desde que se procure a noção em outros contextos dos até agora explorados pela literatura. Com efeito, ao tratar do dízimo, Tomás escreve:

Duas coisas devem ser observadas sobre o dízimo: o direito de recebêlo (ius accipiendi) e os bens concedidos sob esse nome. O direito de recebê-lo é espiritual e resulta da obrigação (debitum) que devemos aos ministros do altar por seu ministério, a de dar os bens temporais aos que semeiam as coisas espirituais e isso pertence somente a eles que possuem o cuidado das almas. Portanto, somente a eles compete ter esse direito (competit hoc ius habere). Quanto aos próprios bens que lhes damos, são materiais e podem servir ao uso de todos. Podem, portanto, ser usados pelos laicos (ST, II II, 87, 3).

A situação descrita é distinta do caso da obrigação de assistência, para a qual não corresponde o direito de ser assistido. Aqui o direito pertence ao ministro que se ocupa das almas. Mesmo que a Igreja tenha autoridade para redistribuir os bens recebidos, é preciso distinguir, insiste Tomás ainda na mesma questão, entre, de um lado, quem os receberá e de que forma e, de outro, quem possui o direito. Na questão seguinte da Suma, ele retoma mais uma vez a assimetria entre obrigações e direitos mostrando que se os ministros recebem o dízimo, eles devem usá-lo para ajudar aos pobres, mesmo que esses não tenham motivo para receber aquilo que foi ganho como dízimo. Portanto, é necessário diferenciar sempre o direito ao dízimo e as obrigações de dá-lo ou de como o usar.

Poder-se-ia objetar ao que foi dito afirmando serem raras as vezes que Tomás emprega ius em sentido subjetivo e que o uso acima é bastante anódino. De fato, muitas vezes deve-se evitar atribuir a Tomás o uso subjetivo. Em outras, no entanto, esse uso deve ser preferido. Um contraexemplo mais apropriado à tese de Villey deveria provir de textos nos quais Tomás vincula ius e potestas, reconhece a importância desse vínculo em contextos jurídicos e utiliza-o para qualificar uma distribuição justa. 
Talvez possamos encontrá-lo em um local um tanto inesperado: o matrimônio. Ora, a instituição medieval do casamento parece ser totalmente estranha aos padrões modernos de subjetividade, uma vez que o aspecto mais subjetivo da relação, o vínculo amoroso que serviria de seu fundamento e determinaria sua duração, não desempenha papel importante para os medievais. Mesmo assim, não há dúvidas de que se trata de um instituto jurídico essencial para a Igreja, pois esta não reconhece como legítimas as ligações fora dele. Ademais, Tomás é explícito ao afirmar que a união entre marido e mulher estabelece uma forma de justiça doméstica distinta tanto daquela entre senhor e escravo quanto da justiça política existente na associação política (ST, II II, 57, 4).

O casamento medieval é uma relação hierárquica na qual o marido tem poder de mando sobre a esposa. Todavia, no interior dessa instituição, as relações sexuais ocupam uma posição diferenciada, pois a hierarquia entre marido e mulher desaparece no que diz respeito a elas. Tomás segue a Bíblia ${ }^{15}$ para dizer que, ao ingressarem no casamento, tanto o marido quanto a mulher perdem o poder (potestas) sobre seus corpos em favor do cônjuge. Ter poder sobre o corpo de outrem equivale a ter um direito de exigir a conjunção carnal (ius petindi debitum). Ambos não podem mais dispor de seus corpos (por exemplo, ingressar em uma ordem religiosa que exija castidade) sem a anuência do outro. Todavia, esse poder não é absoluto e está subordinado à finalidade da união, ou seja, à constituição da família. Essa potestas possui limites para seu exercício e manutenção. Se o marido comete adultério, ele perde o direito ao que é devido (vir amittit ius petendi debitum), sem que isso interfira no direito da esposa, a qual não pode ser punida pelo pecado do marido (SS, IV, 34, 1, 5). Tomás reconhece no casamento, portanto, duas relações distintas. Na primeira, a mulher está sob o poder do marido (uxor est in potestate viri), pois há entre eles uma relação natural de hierarquia e o marido é dito ser o chefe da casa. Na segunda, o casamento começa com a instituição de uma igualdade que surge da renúncia recíproca de poderes com o objetivo de formar os laços de fidelidade. Quem recebe o poder (potestas) passa a ser dotado de um direito específico (ius petendi debitum). Mas a reciprocidade inicial pode ser perdida na constância da união, de tal sorte que o marido pode continuar a ser o chefe da casa, mesmo tendo perdido o direito à conjunção. Para os nossos propósitos, importa assinalar que, aos olhos de 


\section{4}

Tomás de Aquino, a constituição dessa relação jurídica envolve explicitamente o vínculo entre ius e potestas de tal modo que ter um poder sobre o corpo de alguém equivale a ter um direito sobre ele.

Se chamamos a atenção para esses textos, é porque eles mostram que Tomás está explicitamente tratando de temas bastante discutidos à época pelo direito canônico. Seu vocabulário e sua ênfase são, na maior parte das vezes, ligados à filosofia aristotélica. Isso não o impede, todavia, de apropriar-se do modo como os juristas medievais tratavam os direitos ou mesmo de opor-se a eles. A recente obra de Charles Reid (2004) atesta o que acabamos de dizer. Reid analisou detidamente os direitos que constituem as relações domésticas medievais e os principais problemas debatidos pelos canonistas. Mostrou que, em sua Suma, Hugócio defendeu que o direito à conjunção carnal surgiria apenas após à primeira união. Até então, tratar-se-ia de uma promessa futura e, como tal, deveria ser analisada. Enquanto não satisfeitas as condições temporais futuras, o direito não poderia ser exigido (REID, p. 111). Ora, Tomás de Aquino aborda a mesma questão, mas de um outro ponto de vista, perguntando se o marido poderia raptar a esposa da casa dos pais e consumar o casamento pela força. Tomás define o rapto como o sequestro de uma virgem com objetivos sexuais. Assim, o marido não é totalmente inocente, pois pecou ao realizar um ato de violência. Mas ele também não é culpado de rapto, uma vez que possui um certo direito sobre a esposa (aliquod ius in sponsa sua, ST, II II, 144, 7, ad 4). Para Hugócio, haveria o rapto. Para Tomás, ocorreria sua desqualificação.

Um outro contexto onde ius revela sua força está no direito de resistência dos súditos. Ao tratar da relação de subordinação, o De virtutibus diferencia dois tipos: a despótica, na qual a alma governa o corpo assim como o senhor governa o escravo que está sob seu poder, sem que este tenha o poder de resistir (facultas resistendi) e a política, na qual os reis ou príncipes governam sobre homens livres que possuem o direito e o poder de resistir (habent ius et facultatem resistendi). As expressões ius e facultas são empregadas aqui como sinônimas. Não se trata apenas da capacidade ou força para opor resistência às ordens emanadas da autoridade. Por serem livres, os homens possuem um direito que justifica a resistência e que seria supostamente a condição dos livres que não se submetem imediatamente à autoridade. A Suma de Teologia retoma o problema e 
emprega basicamente o mesmo vocabulário, deixando todavia mais evidente a sinonímia, pois o escravo é dito não possuir o direito de resistir (ius contradicendi non habet) e os homens livres são aqueles que o possuem (habent ius in aliquo contradicendi, ST, I II, 58, 2). É bem verdade que o contexto dessas citações não é o de uma teoria política e que Tomás não chega a desenvolver uma teoria da resistência baseada nesse vocabulário. No De Regno, ele sustenta que o povo tem o direito (ius) de instituir um rei, mas se esse se revelar um tirano, não é injusto que ele seja destituído pela coletividade, pois somente ela, e não um homem particular, tem esse poder. Observe-se que a criação do reinado é a transferência perpétua de poder ao rei. $\mathrm{O}$ direito de governar provém dessa transferência que não pode ser revogada pelo povo a não ser se o próprio rei desrespeitar as obrigações para as quais ele foi instituído.

Nada do que afirmamos até agora pretende ser uma defesa de Tomás de Aquino como o inventor da noção de direito subjetivo. Ao contrário, a sua teoria do direito funda-se nos textos clássicos do direito romano lidos à luz da teoria aristotélica da justiça, como julgamos ter mostrado a respeito da noção de propriedade. Mesmo assim, e foi esse o nosso propósito até o momento, Tomás não desconhece os debates jurídicos de seu tempo que exploravam o aspecto subjetivo do direito, como quando ele atribui ao acusador o direito (ius) de ver o culpado punido (ST, II II $67,4)$. Os textos que trouxemos a colação atestam a existência desses elementos na obra de Tomás, sem que ele os tenha sistematicamente empregado no momento de definir o direito. Buscamos assim fundamentalmente evitar o dicotomismo purista com que trabalha Villey entre uma noção exclusivamente objetiva e outra totalmente subjetiva de direitos.

\section{Conclusão}

No início do século XX, a noção de direito subjetivo ganha terreno entre os civilistas franceses interessados nas bases da ciência jurídica e sob influência da escola alemã. Com efeito, atacando aqueles que reconstruíam o sistema jurídico na base da noção de direito subjetivo, Duguit escreve: "o problema do direito subjetivo é sempre esse: há certas vontades que possuem, de maneira permanente ou temporária, uma 
qualidade própria que lhes fornece o poder de se impor enquanto tais a outras vontades? Se esse poder existe, ele é um direito subjetivo que é assim uma qualidade própria a certas vontades e que assim revestidas impõem-se à outras vontades; as quais são reciprocamente investidas de um direito subjetivo em relação às primeiras" (DUGUIT, 1924). Colocado o problema nesses termos, não é difícil perceber como a Declaração dos Direitos do Homem e do Cidadão de 1789, documento central na história francesa, permanece sempre presente no horizonte dos debates. Ora, basta lembrar que a Declaração está repleta de citações tiradas da filosofia dos séculos XVII e XVIII em defesa de "direitos naturais, inalienáveis e sagrados do homem" para dar-se conta de que a crítica de Villey aos direitos subjetivos não passa de um ataque explícito à teoria do direito natural desenvolvida a partir do século XVII (VILLEY,1983). Ou seja, os ataques a Hobbes e ao seu alegado "antecessor" que teria sido Ockham são um instrumento para atacar a própria Declaração e os direitos por ela veiculados e que estão na base do Estado moderno de direito.Voltar à concepção romana e tomista não é outra coisa para Villey do que abandonar os modernos direitos do homem e do cidadão e acusar qualquer teoria moderna que defenda a dignidade humana de estar fundada em uma visão egoísta e subjetivista. Mesmo em sua disputa com Kelsen e no ataque ao positivismo jurídico, é sempre o mesmo ponto que é colocado em evidência por Villey: a superioridade de Tomás de Aquino e de sua interpretação de Aristóteles. Tanto que a apregoada refutação de Kelsen não passa de uma mera contraposição ao direito natural de Tomás, do qual "não podemos nos passar" (VILLEY, 1987, p. 152).

Esse parti pris compromete em grande medida as tarefas do filósofo e historiador do direito, pois a supremacia de Tomás somente poderia ser alcançada mostrando-se que o Ocidente errou profundamente ao desviar da filosofia tomista, leia-se, do catolicismo anterior ao do Concílio Vaticano II. Eis outro alvo que se esconde na querela sobre o surgimento do direito subjetivo. Além de um debate sobre qual teoria do direito natural adotar, trata-se de uma defesa da filosofia tomista como a doutrina oficial da Igreja Católica.

Para alcançar seus objetivos, Villey precisou construir uma oposição histórica que jamais foi tão clara ou pura como ele desejaria. Annabel Brett (1997) e, sobretudo, Brian Tierney (1989) mostraram as fraquezas 
de argumentos que selecionam apenas os textos que melhor convêm a seus propósitos e deixam de lado autores e passagens em sentido oposto ou que trariam dificuldades para a teoria. De modo mais contundente e talvez um pouco exagerado, Sylvain Pirron (2008) reconstruiu a trajetória de Villey endereçando-lhe críticas bastante severas, tanto do ponto de vista dos interesses que moviam o personagem político, quanto acerca do modo como articula e seleciona textos a fim de demonstrar suas teses. Para Pirron, Villey é "um católico conservador ${ }^{16}$, encarnando a velha tradição de hostilidade da Igreja Romana face ao individualismo moderno". Observe-se, contudo, que a crítica ao individualismo moderno não é rara entre pensadores católicos no início do século passado. Ela pode ser encontrada mesmo em Gilson (2007). Todavia, esse afasta-se de Villey ao eleger como o grande responsável por todos os males modernos Descartes e não Ockham. Villey permanece, no entanto, o mais reacionário, como se depreende de suas críticas aos direitos humanos como uma "linguagem indistinta, perigosamente imprecisa, geradora de ilusões e de falsas reivindicações impossíveis de serem satisfeitas”, bem como de sua depreciação da doutrina social da Igreja (VILLEY, 1983 e, sobretudo, 1987). Mesmo assim, a tese de Villey continua ainda hoje a ser difundida $^{17}$ e seguida ${ }^{18}$. Esperamos que o presente artigo sirva para sugerir que ela deve ser tomada com cuidado.

${ }^{1}$ Em sentido contrário, veja-se uma das primeiras reações contra Villey em PUGLIESE, 1954.

2 Mas consulte-se as críticas de COLEMAN (1989) e sua interpretação do De Potestate regia et papali de João de Quidort.

3 Sobre o contexto histórico de surgimento da expressão "direitos humanos", veja-se, em particular, HUNT (2007).

${ }^{4}$ Note-se que as críticas de Tierney não versam tanto sobre o direito subjetivo, mas sobre a tentativa de encontrar os primórdios dos direitos humanos entre os canonistas do século XII. Por concentrar-se nos direitos humanos, Tierney dá pouca importância ao problema dos direitos subjetivos no direito romano.

5 Para uma apresentação geral da noção estóica de incorpóreo: BRUNSCHWIG, 2003.

6 Compilação do direito romano realizada na metade do século VI d. C., sob as ordens do Imperador Romano do Oriente, César Flávio Justiniano e que juntamente com os Institutas, as Novelas e o Código formam aquilo que se convencionou chamar, a partir do século XVI, de Corpus Iuris Civilis. 
7 GAIUS (1991, II, 208): “Quantum ad hoc ius quod lege Papia coniunctis constituitur...” e III, 75: "nam incredibile uidebatur pessimae condicionis hominibus uoluisse legis latorem testamenti faciundi ius concedere."

8 Como o direito de legislar que possuem os magistrados. GAIUS (1991, I, 6): "Ius edicendi habent magistratus populi Romani”.

9 GAIUS (1991, III): “ab imperatore ius Quiritium consecuti essent, si eo iure postea usi essent”.

10 A literatura sobre o ponto é imensa. Consulte-se: GOUREVITCH (1997), MORRIS (1972), TAYLOR (1989), mais recentemente DE LIBERA (2007) e o interessante livro de SHERWOOD (2007).

11 Nessa seção, sigo inteiramente COLEMAN (1998). Veja-se ainda: LAMBERT (1961), KRIECHBAUM (1996), mas sobretudo MÄKINEN (2001) e MÄKINEN e KORKMAN (2005).

$12 \mathrm{O}$ problema adquire contornos mais graves no contexto do debate sobre a pobreza. Com efeito, a Regra da Ordem Franciscana (Regula VI) previa a proibição da propriedade, mas permitia o uso de bens. Em seu comentário, escrito por volta de 1255, Hugo de Digne escreve: "appropriare est rem suam facere sive in suum dominium convertere. Sua autem res est quae transit in arbitrii facultatem ut de ea per se facit habens quod vult, vendendo commutando donando impignorando. Proprietas est ius dominii quo quis dicitur dominus esse rei, quo etiam iure res ipsa dicitur esse sua, id est, domini propria." Editado por FLOOD (1979, p. 147).

13 ST, II II, 66, 7: "Et ideo res quas aliqui superabundante habent, ex naturali iure debentur pauperum sustentationi."

14 A ST lista, com efeito, os seguintes sentidos de ius: a) ipsa res iusta; b) a arte pela qual se conhece o que é justo; c) o local onde é dito o direito (in quo ius redditur) e d) aquele diz o que é o direito, mesmo quando ele diz algo injusto. Nenhum dos casos, contudo, corresponderia ao sentido subjetivo. ST II II, 57, 1 , ad 1.

15 Bíblia, I Cor 7 3:"Uxori vir debitum reddat: simíliter autem et uxor viro. Mulier sui corporis potestatem non habet, sed vir. Similiter autem et vir sui corporis potestatem non habet, sed mulier."

16 Aliás, o próprio Villey reivindica essa condição.

17 Ela continua a ser regularmente publicada e traduzida em diversas línguas, inclusive no Brasil. Ela é usada, não sem alguns reparos, por TUCK (1979).

18 Cf.TIERNEY (1989), reimpresso em TIERNEY (1997), que cita entre os que aceitam ser a invenção de direitos, no sentido subjetivo, uma invenção moderna L. Strauss, J. Habermas e J. Finnis.

doispontos, Curitiba, São Carlos, vol. 7, n. 2, p.47-72, outubro, 2010 


\section{Referências bibliográficas}

Les déclarations des droits de l'homme de 1789.1988. Textes réunis et présentés par C. Fauré. Paris: Éditions Payot.

BRETT, A. 1997. Liberty, Right and Nature: Individual Rights in Later Scholastic Thought. Cambridge: Cambridge University Press.

BRUNSCHWIG, J. 2003. "Stoic Metaphysics". In INWOOD, B., The Cambridge Companion to the Stoics. Cambridge: CUP, p. 206-232.

COLEMAN, J. 1988. "Property and Poverty”. In: BURNS, J. H. The Cambridge History of Medieval Political Thought c. 350 - c. 1450.

Cambridge: CUP, p. 607-649. . 1989. "Guillaume d'Occam et la notion de sujet". Archives de Philosophie du Droit, t. 34, p. 25-32. 2006. "Are there any individual rights or only duties? On the limits of obedience in the avoidance of sin according to Late Medieval and Early Modern Scholars". In MÄKINEN,V. e KORKMAN, P., eds. 2005. Transformations in Medieval and Early-Modern Rights Discourse. Dordrecht: Springer, p. 3-36.

Corpus Iuris Civilis Justinianei, cum commentariis Accursii .... Lugdini, 1627.

DE LIBERA, A. 2007. Archéologie du sujet. Paris:Vrin.

DUGUIT, L. 1924. Traité de droit constitutionnel. Paris: E. de Brochard.

FLOOD, D. 1979. Hygh of Digne's Rule Commentary. Grottaferata:

Editiones Colegii S. Bonaventurae ad Claras Aquas.

GAIUS, 1991. Institutes. Texte établi et traduit pas J. Reinach, quatrième tirage revue et corrigée par M. Ducos. Paris: Les Belles Lettres.

GILSON, E. 2007. Le réalisme méthodologique. Présentation de Th.-D. Humbrecht. Paris: Pierre Téqui.

GOUREVITCH, A. J. 1997. La naissance de l'individu dans l'Europe médiévale. Trad. J-J Marie. Paris: Seuil.

HUNT, L. 2007. Inventing the Human Rights. New York: Norton \& Company. 
KEMPSHALL, M. 1999. The Common Good in Late Medieval Political Thought. Oxford: Clarendon Press.

KRIECHBAUM, M. 1996. Actio, ius und dominium in den Rechtslehren des 13. und 14. Jahrhunderts. Ebelsbach: Aktiv Druck.

LAMBERT, M. D. 1961. Franciscan Poverty. The Doctrine of the Absolute Poverty of Christ and the Apostles in the Franciscan order 1210-1323.

Londres: SPCK.

MÄKINEN,V. 2001. Property Rights in the Late Medieval Discussion of Franciscan Poverty, Leuven: Peeters.

e KORKMAN, P. eds. 2005. Transformations in Medieval and Early-Modern Rights Discourse. Dordrecht: Springer. . 2005b. "Rights and Duties in Late Scholastic Discussion on Extreme Necessity”. In MÄKINEN,V. e KORKMAN, P. eds. 2005. Transformations in Medieval and Early-Modern Rights Discourse. Dordrecht: Springer, p. 37-62.

MORRIS, C. 1972. The Discovery of the Individual 1050-1200. Buffalo: University of Torotno Press.

PIRRON, S. 2008. "Congé à Villey". Atelier du Centre de recherches historiques, Revue électronique du CRH, vol 01: Historiographies de la pensée politique médiévale. [Online] Disponibilidade:

http://acrh.revues.org/index314.html. Acesso 12/07/2010.

PUGLIESE, G. 1954. “'Res corporales', 'res incorporales' e il problema del diritto soggetivo". In Studi in onore di Vicenzo Arangio-Ruiz, III, Nápoles, p. 163-187.

REID, C. 2004. Power over the Body, Equality in the Family. Rights and Domestic Relations in Medieval Canon Law. Cambridge: Eerdmans Publishing.

SHERWOOD, T. G. 2007. The Self in the Early Modern Literature for the Common Good. Pittsburg: Duquesne University Press. 
TAYLOR, C. 1989. Sources of the Self: the making of the modern identity. Cambridge: Cambridge University Press.

TIERNEY, B. 1989. “Origins of Natural Rights Language: Texts and Contexts, 1150-1250”. History of Political Thought 10, Exeter. Reimpresso em TIERNEY, 1997, artigo II.

. 1989. "Villey, Ockham, and the Origin of Natural Rights". In WITTE Jr, J. e ALEXANDER, F. S. eds., The Weightier Matters of Law. Essays on Law and Religion, Atlanta: Scholars Press, p. 1-31. Reimpresso em TIERNEY 1997, p. 13-42.

1997. The Idea of Natural Rights. Studies on Natural Rights, Natural Law and Church Law, 1150-1600, Atlanta: Scholars Press . 1997b. Rights, Laws and Infallibility in Medieval Thought, Hampshire, Ashgate.

TOMÁS DE AQUINO, 1891-1906. Summa Theologiae. Opera omnia iussu impensaque Leonis XIII P. M. edita. Romae: Ex typographia Polyglotta S. C. de Propaganda Fide. Citado como ST

. Summa contra Gentiles. Opera omnia iussu impensaque Leonis XIII P. M. edita. Romae: Ex typographia Polyglotta S. C. de Propaganda Fide. Citado como CG.

1969. Sententia Libri Ethicorum. Opera omnia iussu impensaque Leonis XIII P. M. edita. T. XLVIII. Citado como SE.

1979. De Regno ad Regem Cypri. Opera omnia iussu impensaque Leonis XIII P. M. edita. T. XLII. Citado como De Regno.

TUCK, R. 1979. Natural Rights Theories. Their origin and development. Cambrige: Cambridge University Press, 1979.

VILLEY, M. 1946. "La notion de droit subjectif et les systèmes du droit romain classique". Revue historique de droit français et étranger, p. 201-228.

1948. "Le 'jus in re' du droit romain classique au droit moderne. Suivi des fragments pour un dictionnaire du langage des glossateurs". Conférences faites à l'Institut de droit romain en 1947. Paris : p. 187-225. 
. 1949. "Du sens de l'expression jus in re en droit romain classique". Revue internationale des droits de l'antiquité, 3, p. 417-436. . 1953. "Deux conceptions du droit naturel dans l'antiquité". Revue Historique de Droit Français et Etranger, n. 4, p. 475-497. .1953-1954. "Les origines de la notion de droit subjectif". Archives de Philosophie du Droit, Nouvelle Série, 2, p. 163-187. . 1954. "Sources et portée du droit naturel chez Gratien". Revue de Droit Canonique, t. IV, n. 1, p. 50-65.

. 1961. "Les fondateurs de l'école du droit naturel moderne au XVII" siècle". Archives de Philosophie du Droit, t. 6, p. 73-105. .1962. Leçons d'histoire de la philosophie du droit. Nouvele Edition. Paris: Dalloz.

1963-1964. Cours d'histoire et de la philosophie du droit. Paris: DES. . 1964. "La genèse du droit subjectif chez Guilaume d'Occam". Archives de Philosophie du Droit, t. 9, p. 97-127.

1968. "Le droit de l'individu chez Hobbes". Archives de Philosophie du Droit, t. 13, p. 209-231.

.1975. La formation de la pensée juridique moderne. Cours d'histoire de la philosophie du droit. Paris: Les Éditions Montchrétien. .1983. Le droit et les droits de l'homme. Paris, PUF. _. 1987. Questions de saint Thomas sur le droit et la politique. Paris: PUF. 1995. Réflexions sur la philosophie et le droit. Les carnets. Textes préparés et indexés par M.-A. Frison-Roche et C. Jamin, préface B. Barret-Kriegel et F. Terré. Paris: PUF. .2001. Philosophie du Droit. Définitions et fins du droit. Les moyens $d u$ droit. Réédition présentée par T. Terré. Paris: Dalloz. 2008. Le droit et les droits de l'homme. Paris: PUF. 